\title{
Retorno de un cruzado, de José Jiménez Lozano. Génesis, intertextualidad y originalidad de un proceso de escritura
}

\section{Retorno de un cruzado, by José Jiménez Lozano. Creation, Intertextuality and Originality of a Writing Process}

\author{
Guadalupe Arbona Abascal \\ Universidad Complutense de Madrid \\ arbona@ucm.es
}

\section{RESUMEN}

Este trabajo estudia el proceso de creación de Retorno de un cruzado (2013), vigésimo cuarta novela de José Jiménez Lozano. Partiendo de los comentarios del autor, se consignan las diferentes redacciones de la obra y se consideran las razones literarias que prevalecen en la versión definitiva. A continuación, se exploran las intertextualidades literarias presentes en la obra. Finalmente, se identifica el eje que sostiene la originalidad de la novela: el personaje contador de historias.

Palabras Clave: Literatura española contemporánea; José Jiménez Lozano; Retorno de un cruzado; historia textual; intertextualidad; proceso de escritura.

\section{ABSTRACT}

This paper analyzes the writing process of José Jiménez Lozano's Retorno de un cruzado (2013), his 24th novel. First, taking into account the author's comments about the creation of the text, it presents the different versions and the literary reasons for his final choice. Second, literary intertextualities found in the novel are examined. Finally, the condition of the main character as storyteller is identified as the novel's major source of originality.

Key words: Contemporary Spanish Literature; José Jiménez Lozano; Retorno de un cruzado; Textual Collation; Intertextuality; Writing Process.

\section{INTRODUCCIÓN}

Retorno de un cruzado es la vigésimo cuarta novela del escritor y premio Cervantes José Jiménez Lozano ${ }^{1}$. El protagonista ha sobrevivido a la Guerra

\footnotetext{
${ }^{1}$ Además del Cervantes (2002), ha recibido otros premios y reconocimientos (www.jimenezlozano.com).

Copyright: (C) 2016 CSIC. Este es un artículo de acceso abierto distribuido bajo los términos de una licencia de uso y distribución Creative Commons Attribution (CC-by) España 3.0.
} 
Civil española de 1936, retorna a casa desalentado y hablando con sus sobrinos se despide de un mundo que no entiende y con el que es fuertemente crítico. Si se atiende a la coordenada temporal en la que se desarrolla la narración, la obra se incluye en el grupo de novelas del autor sobre la Guerra Civil. Además bien se podría situar entre las novelas históricas, si seguimos algunos de los criterios que ha tenido en cuenta la crítica para clasificar la obra de Jiménez Lozano. Se han realizado esfuerzos de agrupación valiosos ${ }^{2}$, pero todavía insuficientes. Sus novelas presentan una vastedad de mundos tal que, por el momento, la crítica ha optado por el estudio de obras concretas, aspectos narrativos transversales, ha atendido a las complicidades literarias que se descubren en sus textos o ha puesto de manifiesto el carácter especial de su escritura. Cabe decir también que, considerando un mundo artístico amplio -en géneros y en complejidad-y excelente literariamente, se echa en falta una mayor presencia en los panoramas generales de la literatura española reciente $^{3}$. Bien es cierto que la dificultad de clasificación procede, en parte, de esa singularidad de la obra del autor que Forbelsky ha calificado como la obra de un escritor «fuera y dentro de su tiempo» (2006: 19).

\footnotetext{
${ }^{2}$ Los estudios que abordan la obra del escritor de manera general aparecen en obras colectivos: José Jiménez Lozano (1994), González (2003), Piedra (2005) y De la Rica (2006). Se añaden a estos los números especiales de las revistas Archipiélago (1996) y Anthropos (1983 y 2003). Más reciente es la página web del escritor (http://www.jimenezlozano.com), que reúne bibliografía completa, estudios e inéditos, dirigida por Guadalupe Arbona Abascal y supervisada por el autor. Se presentó en Ávila en enero de 2012.

${ }^{3}$ En los estudios generales de la historia de la literatura, su obra aparece extrañamente silenciada. Santiago Moreno (2010) señala que el autor no aparece en el tomo correspondiente de la obra de Francisco Rico (2000). Tampoco lo menciona Sanz Villanueva (1984; 2010). Sí aparece, con una entrada breve, en Gullón (1993: 794) y en Gracia y Ródenas (2011: 237; 645-647; 722; 941-42). La crítica italiana se había anticipado en este reconocimiento (Morelli y Manera, 2007: 237-239) a una obra publicada, leída y valorada a lo largo de cuarenta años. Entre las aproximaciones de clasificación de la obra, véanse los trabajos de Francisco Javier Higuero $(1991$; 1993; 2013), quien la aborda desde la perspectiva de la memoria y la concepción jimenezlozaniana de la intrahistoria. Medina-Bocos (2005) realiza un interesante recorrido de la panorámica general de la obra, desde el punto de vista cronológico. Pozuelo Yvancos (2003) destaca la originalidad de las «fábulas» de Jiménez Lozano y sienta las bases literarias de esta denominación. Santiago Moreno (2008) divide la obra de Jiménez Lozano en «primeras novelas», donde incluye las cuatro primeras novelas, todas de ambientación histórica; «fábulas», siguiendo la denominación de Pozuelo Yvancos; y «novelas sobre mundo contemporáneo». Alicia N. Martínez Díaz (2011) mantiene esta clasificación de Pozuelo. Blanca Álvarez de Toledo en su tesis doctoral, titulada Apuntes para una poética de las novelas de José Jiménez Lozano: «Historia de un otoño», «Ronda de noche» y «Maestro Huidobro», todavía inédita (2015), introduce una nueva clasificación: novelas sociales (divididas en aquellas que recrean episodios históricos o episodios coetáneos) y relatos legendarios.
} 


\subsection{Posición de la novela en el conjunto de la obra de Jiménez Lozano}

Como se ha dicho, Retorno de un cruzado tiene varios antecedentes narrativos con trasfondo histórico en el reciente conflicto bélico. Entre ellas, La salamandra (1973), Duelo en la casa grande (1982) y Un hombre en la raya (2000a). Se pueden rastrear otros precedentes en las colecciones de relatos cortos, en los que tanto el tema de la Guerra Civil española y sus consecuencias, como el aborrecimiento de un mundo cainita y sin referencias están muy presentes. En este sentido Sherzer considera al escritor «una de las conciencias más claras y contundentes desde el final de la Guerra Civil» (Sherzer 2003: 216) y lo considera un escritor testimonial («yo nómada», Sherzer, 1994: 124). Este motivo, presente en la ficción, lo está en los diarios o libros de cavilaciones, salpicados de reflexiones sobre la historia de España y, especialmente, sobre este periodo. Entre los ensayos que ofrecen una hipótesis crítica sobre esta etapa, habría que destacar Los cementerios civiles y la heterodoxia española, que sale a la luz por primera vez en 1978 y se reedita en 2008; la primera edición es del periodo de la reciente Transición española y la segunda aparece en el marco de los debates sobre la llamada «memoria histórica». Retorno de un cruzado se apoya en estas reflexiones históricas, religiosas y antropológicas. De un modo más sintético y ceñido al tema de las ideas, se apuntan las razones de un enfrentamiento entre facciones y bandos que se sirven de lo religioso para justificar la violencia y la exclusión, en el artículo titulado «E la Guerra Civile divenne una Crociata» (Jiménez Lozano, 1987).

Sobre el telón de fondo histórico, se perfila un protagonista que es además contador de historias; se ficcionaliza la tarea del relatador, que se desdobla en la figura de narrador y sobrino del protagonista, es el segundo quien decide poner por escrito las historias que ha oído contar a su tío. En este sentido, representa un vértice interesante de los varios personajes contadores o narradores que aparecen en la narrativa jimenezlozaniana ${ }^{4}$. Por otro lado, las dos figuras centrales

\footnotetext{
${ }^{4}$ La presencia de personajes narradores es frecuente en la narrativa de Jiménez Lozano. Señalo sólo algunos casos: Duelo en la casa grande (1982) ofrece el largo monólogo de Ojo Virule, que reflexiona sobre el carácter sanador, purgativo y catártico de la narración. El escriba que ha perseguido a Sara en Sara de Ur (1989) revela en el capítulo final titulado «El sello del escriba» sus dificultades y sacrificios para escribir sobre su personaje. El narrador de Los grandes relatos (1991) se presenta en su oficio en el capítulo central, titulado «Los episodios nacionales». Hay un copista en Libro de visitantes (2007) que permite recuperar el Manuscrito del Monte Athos y comparte sus secretos. El mudejarillo (1992) es el texto de un escritor «privado» que se confiesa ante un Inquisidor que le pregunta por fray Juan. Las gallinas del licenciado (2005) finge estar escrita por el sobrino de un comerciante de gallinas que conoce a ese escritor que estuvo en Lepanto. Y un largo etcétera que merecería un estudio detenido. Todos ellos reflexionan sobre el valor de la narración y el oficio de contar historias.
} 
de la novela son expresión de la preocupación constante del autor sobre su oficio, como ha señalado la crítica .

\subsection{Presentación y estructura de la novela}

Retorno de un cruzado cuenta la historia de Pedro Manuel Martín Lodares, que vuelve a casa después de haber participado en la Guerra Civil española como médico de los milicianos y luego de haber marchado a Rusia con la llamada División Azul. Enfermo y dolorido por estas sangrientas cruzadas, el protagonista recuerda con nostalgia su formación en la ciudad de Oleza, donde aprendía la épica y la realidad de los cruzados medievales. Pedro vuelve cansado de las luchas del mundo y, sabiendo que le queda poco de vida, decide despedirse contando lo que ha vivido a sus sobrinos. Uno de ellos hace de narrador y nos relata las conversaciones e historias de Pedro Lodares.

La novela se divide en ocho capítulos que siguen el orden aleatorio y desordenado de la memoria, tal y como lo recuerda, como a retazos, el fingido narrador. Éste intenta reproducir las conversaciones de Pedro Lodares con él y su hermana Lisa; consigna las charlas que tienen como contenido la vida y las peripecias de Pedro, a las que se añaden la lucidez de sus juicios sobre la historia vivida, leída e imaginada. El texto entreteje en la narración la memoria de unos hechos con las consideraciones que nacen de lo vivido, por eso la experiencia del tío Pedro se presenta de modo más completo, en cuanto el relato permite un conocimiento mayor. La novela se ordena en un diálogo que va de tío a sobrinos y de sobrinos a tío. Es decir, por un lado, la experiencia de Pedro se somete a las preguntas de los sobrinos, que no se cansan de indagar sobre las razones de su vivir; por otro, las historias se ofrecen en despedida, porque el protagonista se sabe con un pie en el estribo y quiere dejar las sabidurías adquiridas a Lisa y al narrador. El tono de la obra nace de la conversación que va de la experiencia vivida y juzgada de Pedro Lodares a las preguntas de los sobrinos, es decir, unas veces el tono está marcado por la melancolía del contador y otras por la esperanza de los oyentes.

La acción de la novela se ordena en tres tiempos fundamentales. En primer lugar, está el tiempo marco de la conversación recordada y transcrita por el narrador. Comprende la despedida de Lodares y el coloquio recordador con sus sobrinos. Se reparte a lo largo de los diferentes capítulos y ocupa la práctica totalidad del último (VIII. «Éste no es un siglo»). El segundo tiempo refleja los sufrimientos y padecimientos durante la Guerra Civil (capítulos I. «Historias de tío Pedro» y II. «El paso de la frontera»), con algunas incursio-

\footnotetext{
${ }^{5}$ Hay varios estudios sobre este aspecto: Arbona (2008), Calvo Revilla (2005; 2006a y b), Conte (1994), Domingo (2002), Fernández Urtasun (2006), González Sainz (2003), Higuero $(1990 ; 1995 ; 1999)$ y Piedra (1989).
} 
nes a momentos de la Segunda República y al ambiente prebélico (VI. «Los balnearios» y VII. «La lucha con el Ángel»). El tercer tiempo de la novela es el periodo de formación de Pedro Lodares, situado en el espacio literario de Oleza. A esta ciudad se dedican tres capítulos: III. «Oleza», IV. «El colegio de los treinta siglos» y V. «El hambre y la lepra». Estos tres capítulos están cuajados de desplazamientos que vuelven la mirada a las figuras de los cruzados medievales, cuyas peregrinaciones y fechorías aprende Pedro Lodares en el Colegio Francés de Oleza, recreación de la trasposición literaria de Orihuela que llevó a cabo Gabriel Miró en sus novelas.

\section{GÉNESIS DE RETORNO DE UN CRUZADO}

Afortunadamente para comprender la génesis de la obra se cuenta con los abundantes comentarios del autor a propósito de la escritura de la obra. Éstos permiten descubrir la complejidad de un texto escrito sobre un trasfondo histórico, que presenta el encaje de una recreación de textos literarios anteriores y cuya unidad viene dada por el personaje protagonista.

\subsection{Antetextos y portada}

La primera cita que preside el libro procede del libro Las cruzadas, de la historiadora rusa Zoé Oldenbourg: «Debemos recordar ante todo, como punto esencial, un hecho simple y evidente: que en aquella época el hombre era aún "medida de todas las cosas"». La historiadora se refería al cruzado medieval. Jiménez Lozano, trayendo la cita a un personaje que habita el siglo XX, emite un juicio crítico: el mundo de hoy no tiene medidas humanas para que el hombre tal y como es viva en él, mientras el de las cruzadas sí era un mundo de hombres. Por lo tanto, el fondo histórico sobre el que contrasta la figura de su protagonista no es entre la antropología medieval y la renacentista, sino entre la medieval —el hombre necesitado y limitado- y la contemporánea - o moderna- que se basa en el superhombre. Es la concepción que el personaje protagonista explica a sus sobrinos añorando los tiempos de las Cruzadas: «también sabían que no eran dioses, pero siempre hay que esperar [...] porque aquellos siglos eran siglos verdaderos y se podía vivir en ellos, y esperar los imposibles y, al fin, éstos llegaban» (2013: 171).

La segunda cita de apertura procede de la obra Juicio sobre la historia y los historiadores, del historiador suizo Jakob Burckhardt: «El gran impacto que nos causan las épocas pasadas y las fuerzas que se manifestaban no proviene de la afinidad que ellas podrían tener con nosotros, sino de su ingenuidad; es decir, de su tranquila seguridad de tener razón». También esta cita requiere una explicación porque el uso de la palabra ingenuidad se hace con una serie de 
connotaciones semánticas que se han perdido en el español actual y que no aparecen en el DRAE, como sinónimo de verdad, de convicción, de fuerza. No es aquí sinónimo de simpleza, ni de candor, ni de desconocimiento, sino de seguridad en lo que se vivía. De este modo, el escritor intenta establecer una comparación entre la falta de ingenuidad de la época contemporánea en la que se desarrolla la peripecia de Pedro Lodares y exalta la juventud del mundo que lleva en la memoria el protagonista, situado en el pasado y caracterizado por su ingenuidad, como sinónimo de alegría y seguridad, de lógica y de razón. Lo que Burckhardt descubría en la Edad Media, período que representa la juventud del mundo.

La portada, a sugerencia del autor, reproduce una recomposición del sello de los Templarios (Sigilum Militum Xristi) que representa a dos caballeros - partían en compañía - en la grupa de un solo caballo — símbolo de su pobreza - en marcha hacia Jerusalén y presididos por una cruz roja que, como dice Lodares, hay que rescatar siempre de entre la sangre y aunque sea «bajo tierra» (2013: 103).

La obra se publica en Ediciones Encuentro el 8 de noviembre con formato de libro. Suma 211 páginas y se inserta en la Colección Literatura de Ediciones Encuentro. Se trata de la sexta y definitiva versión del texto.

\subsection{Proceso de publicación}

Las dudas del autor sobre el mérito del relato se plantean en fechas próximas a la producción editorial del libro. El escritor pide ayuda porque no quiere publicar ninguna obra que no sea «hermosa y verdadera» y llega a afirmar que «aunque se ha encariñado con él» — con el personaje porque lo ha «vivido y revivido»- está dispuesto a dejarlo sin publicar (correo del 18 de enero de 2013) si la obra no tiene suficiente valor. Los comentarios del autor también revelan temores a que el tema y el momento histórico de la novela puedan dar pie a interpretaciones políticas. Como veremos, los cambios sobre la primera versión, la más breve, se orientan a evitar el encasillamiento y la adscripción de la obra a un bando. Esto supondría un fracaso completo respecto a la intención de la novela, pues en su centro late el drama de un personaje atormentado por las divisiones políticas y sus terribles consecuencias. La cantidad de intertextualidades son también motivo de preocupación para Jiménez Lozano, porque pueden entorpecer la lectura. Ciertamente, hay muchas en el texto; algunas de ellas sólo pueden ser halladas a través del conocimiento del corpus amplio de la obra del autor, de las glosas autoriales de los estudios intertextuales.

Más cerca de la fecha de salida del texto, vuelve a dudar de la publicación cuando recibe una nota de la editorial para que participe en la campaña de promoción del libro. La manera de reaccionar a la nota refleja la consideración del 
autor de que su obra no puede triunfar en una sociedad de consumo. Sólo gracias a la compañía de los lectores que aprecian su escritura y de otros autores conjura la duda sobre la publicación en una sociedad de consumo.

Afortunadamente, el parón que supuso esta nota no impidió la publicación, aunque las dudas del autor sobre la escritura no cesan, como se puede constatar en este comentario del 5 de diciembre de 2013: «y me revuelven todas mis dudas acerca del narrar [...] no me dejan nada tranquilo [...] si resulta que lo narrado no es más descubridor y más garante de la verdad que lo histórico, si es un puro juego a la comba, por decir algo». Se ve aquí la alta estima del autor sobre la narración que debe ofrecer más verdad —o verdad más humana- que la historia.

\subsection{Proceso de escritura y reescritura}

La versión definitiva de la novela es la sexta. El proceso de redacción y revisión se extiende a lo largo de casi tres años. El anuncio del envío de una primera redacción se realiza el 11 de diciembre de 2011 (se hace efectivo en enero de 2012) y la versión definitiva se envía por correo electrónico el 30 de enero de 2013.

Entre medias, ha habido otras tres versiones de diferente extensión: la primera ocupa 158 folios; la segunda aumenta en 42 folios — tiene 237 páginas-; las versiones tercera, cuarta y quinta tienen 195 folios, que harán las 211 del libro final. El cambio más significativo está entre la segunda versión y las restantes. La razón es que el escritor confía su primera versión a tres lectores, los tres profesores de literatura, y, como consecuencia de las conversaciones con ellos y de sus sugerencias, decide consentir con la propuesta de dar más recorrido a las figuras de los sobrinos, Lisa y el narrador, que han asistido a la conversación con Pedro Lodares y que se construyen sólo en cuanto receptores de las historias de Pedro. Así es como el autor comienza a pensar, en marzo de 2012, en una segunda parte para contar algo sobre las huellas que ha dejado Lodares en ellos. La escribe en mayo de ese mismo año y la envía en junio. Se añade así el capítulo IX, titulado «Dos trozos de lacre», que no aparece en la versión definitiva.

El capítulo IX incluye un resumen de las peripecias de Lodares y sugiere que son más de las contadas. Este recurso metonímico de la narración se logra a través de dos modalidades. La primera consiste en describir los constantes sueños y desmayos de Pedro Lodares, que impiden escuchar otras historias que quedan en los límites de sus somnolencias. La segunda viene dada por la referencia a los disfraces o atuendos que guarda en un baúl; cada uno representa una parte de su vida y con uno de ellos ha de ser enterrado. Se anuncia así la última cruzada de Lodares y se presentan de manera resumida las anteriores cruzadas o vidas con las que se ha identificado el protagonista. 
Ahora bien, la parte más novedosa del nuevo capítulo se refiere a la herencia de Pedro que, de algún modo, ha sobrevivido en las dedicaciones profesionales de los sobrinos. El narrador sueña con ser funcionario de correos, pero al estilo de los correos del Zar, por eso imagina literariamente y se ensimisma con las aventuras de Miguel Strogoff, el personaje de Julio Verne. Aun a sabiendas de que eso es imposible, porque «ya estaban borradas las rutas de correo que tenían aquellos antiguos Cruzados, que conocían a medio mundo y medio mundo les conocía a ellos» (Cap. IX, inédito), y porque la geografía del mundo parece haber encogido ${ }^{6}$. A pesar de todo, la mesa del sobrino de Pedro está llena de mapas, cuyas veredas y caminos se pueden revivir a través de la epístola. Las cartas son el origen de la literatura, un emisor que se comunica con un destinatario, uniendo así espacios y tiempos y posibilitando el viaje:

Había sobre mi mesa decenas de mapas de ciudades, caminos, carreteras, veredas y cañadas, mares océanos y pasillos aéreos, anchos y estrechos; y fotografías, sobre todo de trenes, estaciones, sus salas de espera, y sus fondas, que tanto le habían gustado también a tío Pedro; y luego más fotos de avionetas, y trineos, y de fachadas de casucas y de buzones solitarios entre ellas, o de Casas de Correos como palacios, con una pared entera de buzones que ponían «Letters», «Lettres», «Lettere». Y sólo querían decir «Cartas», pero ¡como si fuera Literatura! ¡Qué bonito! (Cap. IX, inédito).

La herencia del protagonista en el sobrino es clara: la vocación de contador de historias del tío pasa a ser la de narrador en el sobrino. Uno y otro han unido espacios y han recreado tiempos.

Por su parte, Lisa es profesora: «Ella se había empeñado en ser profesora de Bachillerato, aunque tío Pedro la advirtió que eso iba a ser un dolor de cabeza y dos de corazón, pero no había hecho ningún caso» (Cap. IX, inédito). Lisa no sigue las advertencias de su tío, pero sí cumple la vocación secreta de Lodares, que, a juzgar por el coloquio que mantiene, es la de seguir la máxima de prodesse et delectare cada vez que narra algún episodio a sus sobrinos. También, como el tío, los dos sufren las contradicciones del mundo en el que les ha tocado vivir. Lisa padece la ignorancia de quienes convierten la historia en espectáculo circense para diversión y mofa y el narrador ha de conservar la memoria de un mundo y de una manera de pensar perdidas.

Ahora bien, las tristezas que dejan estas vidas — podrían parecen abocadas al fracaso- no terminan en esta enumeración de las contradicciones y dramas que deben soportar uno y otra. Jiménez Lozano añade al final de este

\footnotetext{
${ }^{6}$ «La geografía del mundo entero había como encogido y un pueblo o ciudad entre los hielos en Alaska era igual a otro pueblo entre los hielos de Rusia y con el silencio del frío casi se oían los bisbiseos de una aldea en la otra; y otras veces encogían hasta los nombres, y una aldea en África o en Asia, o también en la América española, tenían tres o cuatro consonantes seguidas al principio de su nombre» (Cap. IX, inédito).
} 
IX capítulo inédito una escena, detenida en el tiempo, que se asemeja en algunos detalles a los pintados por Georges de $\mathrm{La} \mathrm{Tour}^{7}$ o a los que aparecen en una estancia holandesa ${ }^{8}$ :

Estaba allí de pie y, después de mirar por la ventana, que daba al jardincillo y ella había abierto, volvió a su silla de paja, se sentó, se quitó el collar de cuentas de coral, y lo dejó sobre la mesita, que estaba junto a esa ventana, y sobre la que desde siempre había habido unas cuantas revistas y unas carpetas con fotografías, una palmatoria antigua con un cabo de vela, y en un plato pequeño, de taza de café, una caja de cerillas y dos trozos de una barra de lacre (Cap. IX, inédito).

Cada uno de estos objetos tiene un fuerte simbolismo en el imaginario de Jiménez Lozano. Interesan ahora los dos trozos de lacre, porque apuntan a cómo se pueden conocer los secretos del mundo, o cómo se podrían haber conocido de haber llegado a ser un capítulo de la novela, porque el lacre abre y cierra esos significados escondidos. Y el final — de este posible capítulo y de la posible novela - hace sentir al lector la caída de esos dos pedazos de cera y las cerillas como la presencia de la esperanza que albergan los dos personajes: la de hallar los secretos del mundo. Así, cuando los lacres caen al suelo, el narrador le dice a su hermana: «Son exactamente como los que, de niños, guardábamos porque eran muy bonitos, y porque, además, nos parecía, que, con ellos, podíamos abrir y cerrar todos los secretos del mundo. ¿Te acuerdas?». A lo que Lisa responde: «-Y claro está que podíamos; y podemos» (Cap. IX, inédito).

El final que ha prevalecido en la versión definitiva es el que aparece en el capítulo VIII, que hace honor al título: «Éste no es un siglo». Pedro Lodares tiene cada vez más desmayos y, aunque los sobrinos esperan más historias, se sabe por el narrador que muchas veces se despierta creyendo que «ha llegado», cabe suponer que a otra vida. Se asiste a la cercanía de la última cruzada: la muerte de Pedro Manuel Martín Lodares. Este final casa mejor con la intención del escritor, que sitúa la génesis de la novela en la encarnación del personaje protagonista.

El truncado capítulo IX constituía una segunda parte de la novela que daba continuidad al legado existencial de Pedro Lodares en sus sobrinos y le robaba ese final de melancolía predominante en el resto de la obra. Por eso, tras varias conversaciones con lectores de los originales antes de la publicación, llega a la conclusión de que el capítulo IX sería un añadido innecesario: «quizás no sólo pierde el aroma de la melancolía, sino que en cierta manera en-

\footnotetext{
${ }^{7}$ Jiménez Lozano ha dedicado muchas páginas a este pintor, cf. Retratos y naturalezas muertas (2000b).

${ }^{8}$ La admiración por las estancias pintadas por los artistas holandeses se observa también en el título de uno de sus libros de conversaciones (Galparsoro y Jiménez Lozano, 1998). Varios de los capítulos del ensayo Los ojos del icono (1988) recuperan la atmósfera detenida de esta escuela de pintura.
} 
dulza o lima las puntas, esquinas y filos, con piedad desde luego, pero arreglándolos de algún modo» (correo del 23 de julio de 2013).

Las razones literarias del autor para concluir en el capítulo VIII la novela son explícitas. A ellas se podrían añadir las que se han apuntado a lo largo de estas páginas y que se desarrollarán en el último apartado referido a la originalidad, porque la coherencia del texto y su unidad se sostienen en la figura de Lodares y en su despedida de este mundo, tras el retorno a un mundo ensangrentado y partido por su eje. El añadido de las vidas de los sobrinos es parte de una nueva narración.

\section{INTERTEXTUALIDADES LITERARIAS EN RETORNO DE UN CRUZADO}

En la obra Retorno de un cruzado se descubren numerosas huellas, alusiones y referencias a otras obras literarias. Es lo que el escritor ha denominado complicidad literaria. Nombra así a esas resonancias de otras obras de arte y experiencias artísticas en sus textos. Resonancias que se producen a diferentes niveles: el nivel que agrupa las reflexiones sobre el quehacer propio del escritor, las huellas de modalidades y géneros literarios en los que se inscriben las historias, y la recreación de categorías ajenas (espacios, tiempos, personajes, etc.) en la propia. La crítica ha denominado a este proceso intertextualidad, si nos atenemos al término que más recorrido ha tenido y que difundió Julia Kristeva (1978) a partir de sus estudios sobre Bajtín. Lo que por su parte, Genette llamó en 1989 «transtextualidad» y que después ha tenido tan largo y fecundo recorrido de discusión teórica (Steiner, 2007; Guillén, 1985; Riffaterre, 1979; Orr, 2003; entre otros)

Las intertextualidades o complicidades literarias en la obra de José Jiménez Lozano responden a un modo de hacer propio lo ajeno y al diálogo artístico mantenido con lo otro. Jiménez Lozano se ha referido a este proceso como el aroma (Jiménez Lozano y Arbona Abascal, 2010: 161-193) que dejan las obras leídas y la nueva forma de mirar el mundo que transmiten. Subyace la concepción de que lo leído en complicidad genera un cambio en el ánimo del lector y es potencial fuente de un nuevo mundo imaginario. El término complicidad responde a una consideración general que se concreta en las presencias rastreables en la obra. En este sentido, Jiménez Lozano sigue de cerca la acuñación azoriniana de la fragancia del vaso (Azorín, 2006: 95), que señala el perfume que persiste en el vaso —en el lector/escritor- de las obras leídas y revividas, exploradas e imaginadas.

El autor define también este intercambio como una extraña forma de amistad: «esas grandes amistades se hicieron una verdadera trama para cuajar luego en parentescos y en complicidades. ¿Por afinidades electivas, que decía Goethe? No lo sé. Pero creo que las aventuras espirituales son, más bien, fascinaciones y secuestros» (Jiménez Lozano, 2003: 166). Estas amistades, reco- 
nocidas por el autor, son el origen de todo un proceso textual, más o menos consciente, que abre al estudio de la crítica, a fin de comprobar la presencia de estas obras, su manera de concretarse, la originalidad dentro del significado completo de la obra, y la novedad que aportan al conjunto de la historia de la literatura.

Para la clasificación general de los hipotextos o huellas en Retorno de un cruzado, se parte de la apuntada por Genette, que señala dos tipos: secretas y manifiestas. Hay dos novelas con las que el escritor ha establecido una línea de complicidad secreta: Incierta gloria (1956), de Joan Sales, y Miserias de la guerra, de Pío Baroja (1951) . Las dos se establecen como polos de complicidad sobre el trasfondo histórico de las vicisitudes vividas en la madurez del personaje de Jiménez Lozano, correspondientes a la Guerra Civil española y sus antecedentes. Este periodo se describe como una trampa «o liga de cazar personas, y, como poco, aunque te escapases de ellas y de la muerte, te sacaban a tiras la carne viva del cuerpo y la del alma» (Jiménez Lozano, 2013: 14).

Incierta gloria es una novela epistolar, dividida en tres partes: las cartas que Luis Brocá escribe a su hermano desde un frente aragonés al que se ha desplazado para seguir la figura de Solerás, anarquista al que admira (I); las cartas de su mujer, Trini, a Solerás desde Barcelona (II); y las anotaciones de Cruells, amigo de Luis Brocá y de Solerás (III). En la novela de Jiménez Lozano se recrea también un frente muerto que sirve de fondo a los dos primeros capítulos de la novela. Se trata de la pintura de un espacio en el que se refugian combatientes de retaguardia que, funestamente, se divierten con calaveradas y teatros de muerte e ignominia:

Para tío Pedro las cosas habían estado bastante tranquilas desde el principio en aquel lugar al que le habían destinado, pero había venido complicándose luego porque la paz en aquella región, con sus frentes muertos, había enloquecido o amodorrado las cabezas y podrido muchas cosas, y los corazones y las almas. Y el territorio aquel se iba convirtiendo en refugio de todos los que no querían ir a luchar contra el enemigo, sino que les gustaba matar a gusto y a capricho y sin que las víctimas se defendiesen, que era lo que pasaba siempre en todos los bandos cuando se pudrían (Jiménez Lozano, 2013: 29).

Además de esta referencia general, en la novela que nos ocupa aparecen hasta once veces el juego macabro con los muertos, el rumor de las calaveras dando en el suelo, o la profanación de cementerios e iglesias ${ }^{10}$. Este leitmotiv está también presente en las cartas de Brocá.

${ }^{9}$ Se prescinde aquí de la presencia secreta de Simone Weil, que ha puesto de manifiesto Arbona en el posfacio de la novela por ser de carácter histórico más que literario (Jiménez Lozano, 2013: 192-193). La presencia de Weil está implícita en estas líneas: «los extranjeros que habían venido a la guerra de España fascinados como pájaro por serpiente, o como persiguiendo a una Perseida, o a blanquear sus huesos en una tierra prometida. O como enviados a perder la guerra como todos los españoles de un lado y del otro» (2013: 22).

${ }^{10}$ Cf. Jiménez Lozano (2013: 16, 17, 18, 19, 21, 23, 29, 35, 37, 47 y 172). 
El segundo aspecto que revela la complicidad literaria es la pintura existencial de los dos protagonistas. El yo dramático es una característica de los dos. Brocá, de Incierta gloria, es un buscador incansable que anhela una razón para lo efímero de la historia y una explicación para el ansia de infinito $^{11}$. Así lo piensa mientras contempla la nube espléndida que pasa (lo efímero) y la firmeza de la roca (la eternidad): «Tengo que vivir [...] tengo que darme prisa en vivir antes de que mis huesos sean arrojados a la buitrera sin fondo que nos espera; tengo que vivir, pero ¿qué hay que hacer para vivir? ¡Vivir!» (Sales, 2012: 49). De otro modo, es dramático también el viaje incansable de Pedro, que es un cruzado de todas las cruzadas y que está marcado y cojo, como Jacob, por haber luchado con el ángel (Jiménez Lozano, 2013: 141-150) en su búsqueda.

El tercer elemento de complicidad literaria descansa en las razones que transparenta la forma epistolar de la obra de Joan Sales. Retorno no es una novela epistolar, pero se sustenta en un andamiaje - la conversación- que reproduce directamente las voces y los testimonios de los personajes. Jiménez Lozano, con otra modalidad literaria afín a la epistolar, el acercamiento a las voces de los personajes a través de una mediación amorosa y fiable — la del sobrino-, finge reproducir un diálogo realizado oralmente. Este parentesco entre un epistolario fingido y la transcripción referida de una conversación actualiza formal y explícitamente los elementos de una comunicación en la que está muy presente un yo que se dirige a un tú.

La segunda obra en la que Jiménez Lozano encuentra sugerencias literarias para la suya es Miserias de la guerra, de Pío Baroja, obra publicada en 2006 gracias a la edición de Miguel Sánchez Ostiz a partir de dos borradores mecanografiados de Baroja de 1950 y 1951. La novela es la primera entrega de la trilogía sobre la Guerra Civil que proyectó Baroja. Jiménez Lozano no tiene recuerdos detallados de la contienda y tampoco de sus antecedentes, pero reconoce en el relato testimonial de Baroja algunos rasgos de las historias que oyó contar cuando era niño, o leyó o estudió después en la Universidad: «Son los relatos ya académicos y otros anecdóticos oídos contar en mi niñez y adolescencia, de historias que habían tenido lugar en mi pueblo y otros del entorno, y otros relatos de Madrid adonde me llevaban con frecuencia al médico» (correo del 16 de octubre de 2013). Parte de la vida de Lodares transcurre en Madrid en esa época: «a tío Pedro le dio tiempo de acabar la carrera de Medicina, no lo tuvo para que le dieran el título y, esperando la entrega, vivía allí, en Madrid [...] y no estaba lejos del hospital al que iba cada día para aprender el oficio con sus trucos, habilidades y saberes» (Jiménez Lozano,

\footnotetext{
${ }^{11}$ Arbona hace referencia en el posfacio (Arbona, 2013: 175-210) de Retorno de un cruzado a este carácter dramático de la obra - el abismo entre el mal sufrido y el ansia de gloria- cuando comenta la confesión del autor que precede a la obra literaria propiamente dicha.
} 
2013: 141). En esos años de desórdenes que Baroja describe bien, matan al cuñado de Lodares y padre de Lisa y del narrador (2013: 141-142).

Miserias de la guerra finge reproducir dos testimonios directos. En primer lugar, el que se recoge en las notas de los Diarios de Carlos Evans, militar y diplomático inglés, que decide permanecer en España para observar los desórdenes que se produjeron en Madrid a partir de 1934; en segundo lugar, las cartas de su chofer, Will (o Bernabé William), contándole a Evans los terrores y violencias de la Guerra Civil, una vez que su jefe se ha marchado. La creación de dos narradores observadores permite a Baroja guardar una distancia respecto a lo narrado y dar la versión de los acontecimientos desde la perspectiva del extraño - del extranjero, del que viene de fuera- y, como tal, tiene libertad para mezclarse y tratar de comprender las dos facciones. Esta posición de extrañeza respecto a la violencia y las adscripciones políticas la comparte también Lodares. La observación crítica de la voz del inglés barojiano intenta ser ecuánime, pero a veces roza la desesperanza cuando ve un país donde se queman iglesias, se mata por una bandería política, se adoctrina a los niños, se da carta de ciudadanía a la propaganda y se exaltan los instintos de violencia, odio y venganza. La obra barojiana tiene la estructura de una serie de escenas o cuadros que son el resultado de las exploraciones del diplomático inglés y de su conductor de diferentes lugares madrileños: el Retiro, la Gran Vía, la Ciudad Universitaria, la calle Embajadores, Montera, etc. Este carácter escénico puede, a menudo, más que el personaje. En realidad, el observador inglés es una trasposición literaria del Baroja exiliado en París, que recibe noticias de Madrid a través de las visitas de los amigos a la capital francesa, y los relatos le permiten hacer una serie de reflexiones sociales e históricas. No es así en la obra de Jiménez Lozano, donde el personaje y la historia que traza son el centro.

Ahora bien, Lodares, como en cierto modo Evans y Will, es extraño. Lo es por familia y por ello preguntan los chicos: « $i \mathrm{Y}$ por qué eran extraños los Lodares, tío Pedro?» (Jiménez Lozano, 2013: 51). Lodares es extraño porque es cruzado ${ }^{12}$ y porque no pertenece a ninguna facción ${ }^{13}$.

El segundo grupo de hipotextos que se pueden hallar de modo más inmediato en la obra son aquellos que se muestran de manera explícita. Los pri-

12 «Los hijos, sobrinos y nietos de un cruzado, antes de los quince o dieciséis años que tienen éstos, ya se despedían de la infancia y se les armaba caballeros, y sabían que, en cualquier momento, debían ir a Jerusalén. Y andando, cargando con su armadura y el peso de los amores que dejaban en casa, y con las dudas de si volverían, o morirían o serían hechos esclavos, y las certezas de que, si volvían, serían extraños para los suyos y para el mundo entero» (Jiménez Lozano, 2013: 98).

${ }^{13}$ «Y, además, porque nuestros abuelos eran gentes de pocas palabras y sin ninguna pertenencia a cofradía o facción ninguna, y simplemente fueron gente contraria al siglo, desde que los siglos dejaron de serlo, un par de cien años atrás, más o menos, cuando comenzaron a mermar los pensares y sentires y comenzaron a brotar los pareceres como ortigas» (Jiménez Lozano, 2013: 107). 
meros son de carácter puntual: se trata de alusiones a obras, personajes y situaciones literarias. De un total de sesenta referencias literarias manifiestas y encontradas ${ }^{14}$, doce son bíblicas ${ }^{15}$. Todas ellas hablan de esa variedad de complicidades literarias o de esas conversaciones que están en la urdimbre de Retorno de un cruzado.

Dentro de este grupo, hay dos hipotextos que se manifiestan en más de una categoría y de modo transversal. Su presencia es continua. En primer lugar, las novelas de Nuestro Padre San Daniel: novela de capellanes y devotos (1921) y El obispo leproso (1926), de Gabriel Miró, de las que se descubren recreaciones de episodios, figuras, espacios e historias en la de Jiménez Lozano. En segundo lugar, el personaje de don Quijote, cuya presencia es compleja, ya que Lodares se mueve en un doble proceso de identificación y distanciamiento respecto a la figura cervantina.

De las novelas de Miró se recrean varias categorías: el espacio y los personajes. La infancia de Lodares transcurre en la ciudad literaria de Oleza, transposición mironiana de Orihuela. La Oleza de Jiménez Lozano se inspira en ésta y se mezcla con la localidad granadina de Guadix: «No es que Guadix sea una geografía, pero es un paisaje interior nacido de la añoranza de mis charlas y viajes por aquella ciudad -y alguna visita y algún archivo o cartas que nos dejaron leer en una casa conocida» (correo del 27 de diciembre de 2012). A la configuración espacial contribuyen también las referencias a los Cruzados medievales, que fueron a Constantinopla, ciudad visitada imaginariamente por el escritor ${ }^{16}$, cuyas aventuras aprende Lodares en el Colegio. A su vez, la imagen del Cruzado se inspira en las sugerencias que provienen de las murallas de Ávila, ciudad de referencia durante la infancia del escritor nacido en Lan-

\footnotetext{
${ }^{14}$ Jiménez Lozano (2013): Libro de oración y meditación, del Padre Granada (18); dos referencias a la Oda VII de Fray Luis de León cuando habla de España como «espaciosa y triste» (19 y 148); El licenciado Vidriera, de Miguel de Cervantes (26), «El capote», de N. Gogol; Ilíada, de Homero (47); Claudia, Lesbia y Safo (59); Los caballeros de la Tabla Redonda (59) y los Andantes (59); la poesía de Mosén Cinto Verdaguer (60); el Jardín de las Hespérides (69); Proust (71); la Beatrice de Dante (72); Petrarca (73); Pandora (77); Péguy (77); el Infierno de Dante (77); En Flandes se ha puesto el sol, de Marquina (83); Don Juan Tenorio, de Zorrilla (83); La Malquerida, de Benavente (83); Hamlet (98); «El honorable batallón de los jumentos», de James Francis Stephens (96); Marcial, Juvenal y Ovidio (111); Ars Amandi (111); Tristia (111); Safo (111); Catulo (111); Las veladas de San Petersburgo, del conde Joseph de Maistre (114); Maestro Echart (117), Descartes (121); Romeo y Julieta (161); Tristán e Iseo (162); Kempis (163); Alicia en el país de las maravillas (129); El gabinete del Doctor Caligari (129); Frankenstein (129); El Correo del Zar (131); Madame Bovary (134); Anna Karenina (134); Numancia (137); Carmen, de Merimée (137); Demonios, de Dostoyevsky (138); Ortega y Gasset (169).

15 Véanse en Jiménez Lozano (2013): Judas (26); Biblia vieja (32); Valle de Josafat (45); Job (61); Liturgia (61); Jardín del Edén (69); Sodoma y Gomorra (69); «Dios lloró cuando el ejército del Faraón se ahogó en el Mar Rojo» (102); las picardías de la Biblia (111); «quien ve a Dios muere» (123); Jacob (27); las lentejas de Esaú (28).

${ }^{16}$ Cf. Jiménez Lozano (2010).
} 
ga. La ciudad en la que se forma Lodares es, por tanto, una especie de collage de varios espacios recreados. A éstos se suman aquellos que provienen de las ciudades y los mapas conocidos gracias al Colegio Francés, donde los sabios y buenos maestros inician a Lodares en una historia de treinta siglos. Se trata de un desarrollo creativo del Colegio de Jesús mironiano (Jiménez Lozano, 2013: 64). Oleza es una ciudad de tertulias donde el conocimiento de las lenguas es habitual y la filosofía permite la sabia conversación en el barrio Latino. Además, la ciudad recibe la apelación de «Edén de Oleza», pues acoge los amores de Lodares y Lisa María de las Nieves, cuyas «ascendencias no eran de la carne, pero encendían ésta, como la Beatriz de Dante exactamente» (2013: 72).

En este espacio complejo, se ha dado nueva vida a personajes mironianos ${ }^{17}$. Jiménez Lozano crea un «obispo leproso»: la figura de este personaje preside desde el título la segunda novela de la dilogía mironiana y es una presencia latente en la ciudad a pesar de su discreción y encerramiento. Delgado y enfermo, no gusta de la pompa y se deja acompañar por los más sencillos de la ciudad. El obispo leproso de Jiménez Lozano aparece también caracterizado por su enfermedad, su sabiduría y su amor a los pobres. La diferencia es que su retrato se nos da de una vez (Jiménez Lozano, 2013: 115). Su sabiduría aparece emparentada por otras figuras del arte: «Dormía mal y parecía leer eternamente por las noches como el Doncel de Sigüienza está haciéndolo en su catedral, el Inquisidor del Corro en San Vicente de la Barquera, el obispo Alonso de Madrigal en Ávila y Dante en Rávena» (Jiménez Lozano, 2013: 115). Su enfermedad procede de la compasión que le suscitan el hambre y la desgracia de los más pobres y su apariencia refleja su pureza: «aquel sordo sufrimiento invadió del todo su cuerpo y su alma; y su piel se le puso blanca y como transparente, y todo él parecía translúcido y alabastrino como si estuviera convirtiéndose en estatua orante de su propia tumba» (2013: 118).

La alegre doña Corazón corretea por las páginas de Retrato con vida nueva. Las posibilidades de la pastelera se multiplican desde las sugerencias del nombre. Es la dueña de la confitería «El Horno Francés», «tienda de dulzuras» (2013: 161). Escucha en silencio las conversaciones de los «ruiseñores y otros pájaros igualmente melancólicos, cuando están bajo la penumbra o la umbría a las que siempre se acogen» (2013: 161). Vende pastas con formas de corazón y tiene una placa en la puerta que representa el sagrado Corazón de Jesús. Además, protege los amores de Lodares y Lisa María de las Nieves.

${ }^{17}$ Y sobre ellos, Jiménez Lozano se permite un juego intertextual explícito; así se siente cuando uno de los chicos del colegio de Lodares pregunta al señor deán: «- $i Y$ es verdad que por aquí hubo lepra y hubo un obispo leproso? ¿Y es verdad que hubo un cura en la catedral que quemaba los bigotes de los ratoncillos con su cigarro? ${ }^{17}$ ¿Y es verdad que una señora o señorita era tan dulce y amorosa que se llamaba doña Corazón? -Esas son imaginaciones y novelerías —dijo el señor deán» (Jiménez Lozano 2013: 71). 
Estos amores imposibles se inspiran en varios amores literarios (Romeo y Julieta, Dante y Beatrice, Tristán e Iseo), que aparecen como términos de comparación. Por un lado, muestran la universalidad de la experiencia amorosa; por otro, los rasgos del amor prohibido, imposible o ideal. La referencia mironiana es clara: la historia entre el hijo de don Álvaro y Paulina, Pablo Galindo, y María Fulgencia, apodada la Monja (Miró, 1943: 912-938).

La sombra de don Quijote de la Mancha en Pedro Manuel Martín Lodares se sustenta en que el presente vivido de ambos personajes resulta de la actualización de una época pasada. Así lo explica Jiménez Lozano: «Lo más que diría es que se apoya constantemente en las Cruzadas - aun sabiendo que no son angélicas - como don Quijote se apoyaba en la caballería andante, y le permite a sus sobrinos y a nosotros ver el mundo y seguramente aspirar a ser inocentes, o no tener complicidades en sus tramas de maldad o estupidez» (correo del 8 de marzo de 2012).

Ahora bien, las diferencias son grandes. Aunque no se pueden presentar de manera exhaustiva aquí, se apuntan a continuación algunas. Por ejemplo, si Alonso Quijano cree ser un caballero andante, Pedro Lodares actualiza la cruzada, en cuanto eso significa no ser cómplice ni con la maldad ni con la estupidez del mundo. Si Quijano vive loco porque se cree en sentido literal caballero - con toda la complejidad que encierra la locura de don Quijote-, Lodares es extraño porque sus peripecias persiguen el ideal que buscaron los cruzados (desenterrar la cruz de la profundidad de la tierra). Quijano sale en busca de aventuras porque quiere emular las de los caballeros, mientras que Lodares padece las cruzadas que no busca. Otra diferencia importante para entender el sentido de la obra es que Lodares vive en un mundo que no comprende y que está partido por el eje y le duele, mientras que don Quijote vive en un mundo que es como su casa y lo juzga sencillamente como «alma de cántaro que es». Esta diferencia estimuló una correspondencia entre el escritor y su interlocutor epistolar porque el escritor se revolvió con la denominación de «alma de cántaro» para su protagonista ${ }^{18}$. Jiménez Lozano considera que su protagonista es un espíritu crítico que no se identifica con el mundo, sino que padece sus atrocidades. La diferencia entre don Quijote y Lodares es su conciencia del mundo: la melancolía de Lodares nace del desengaño ante un mundo roto y ensangrentado, mientras que don Quijote pone de manifies-

${ }^{18}$ «Una pequeña objeción no a su interpretación quijotesca, sino a su formulación de «"alma de cántaro": me parece que tío Pedro no es un cándido, ni un inocente, ni un iluso o un platónico. Conoce bien el mundo, sabe que está desquiciado, y sabe que los cruzados pueden ser una escoria. Por supuesto que está fuera de su tiempo, pero conscientemente, digamos que como Franz Grillparzer, decía en pleno siglo XIX que él venía de otro tiempo y esperaba ir a otro, o, como Bergamín tan amigo de piruetas retóricas explicaba a sus amigos comunistas que su mundo no era de este Reino. Está muy bien dicho [...]. Quiero decir solamente que tío Pedro no es un ingenuo o cándido, como don Quijote» (correo del 8 de marzo de 2012). 
to algunas injusticias de un mundo humano a través de sus descabelladas aventuras. El modo de hacerlo es distinto. Lodares presenta el mundo lúcidamente, mientras que el segundo, encarnando la candidez sin malicia y con mucha sabiduría, logra hacer comparecer la doblez o crueldad del mundo ante nuestros ojos. En este sentido, Jiménez Lozano añade el valor que puede llegar a ejercer la creación de una figura cándida en el paisaje de un mundo: «Pienso que un "alma de cántaro" lo es porque a nosotros nos parece fundamentalmente ingenuo, pero, pensándolo más profundamente, quizás es fundamentalmente inocente, y quizás sí sabe cómo funciona el mundo y que la maldad existe, pero él no participa de ella, sino en otra máquina de inocencia» (correo del 14 de marzo de 2012).

Esta concepción del autor se explicita en la novela. Así, el tío Pedro, hablando con sus sobrinos y dando una vuelta de tuerca que salva todas las distancias, hace al Quijote heredero de las Cruzadas; es decir, sin éstas no se hubiera podido asistir a las aventuras del ingenioso hidalgo: «Cruzadas y Cruzadas [...] alumbraron con su luz antigua esta singular alma de cántaro de Don Quijote. ¿Y puede nadie recibir un más alto favor del cielo que un alma de cántaro?» (Jiménez Lozano, 2013: 170).

A pesar de las similitudes entre las figuras, basadas en la comparecencia de un mundo antiguo en los dos personajes literarios (Quijote-caballeros, Lodares-cruzados), las distancias se refieren a los dos mundos representados y al tipo de que mantienen uno y otro.

Lo que parece prioritario, en este primer estudio panorámico de Retorno de un cruzado, es revisar aquellos momentos de la peripecia del protagonista en que la Cruzada remite a una complicidad literaria. En efecto, la configuración de Lodares como nuevo cruzado se organiza en torno a las etapas de la vida del personaje. Estas etapas se conciben como respuestas a acontecimientos y situaciones con las que Lodares se compromete críticamente y son las que conceden originalidad a la novela. En este sentido, se puede hablar de un personaje creado en un sentido vocacional, porque el narrador muestra su singularidad en la manera en la que responde a las solicitaciones de las coordenadas en las que se le sitúa. Así, se descubre la condición de cruzado cuando, siendo todavía un niño, el médico que le quita las anginas le dice que con una cruz roja en el pecho será tan valiente como un templario (Jiménez Lozano, 2013: 157). La anécdota aparentemente casual se consolida como polo de comparación, desarrollado en múltiples situaciones y batallas contra sus contradicciones. La cruz roja que el cirujano descubre en el pecho del niño se convierte en ideal que debe mover la vida («rescatar la Cruz verdadera aunque fuera bajo tierra y cargar con ella» (Jiménez Lozano, 2013: 103). Móvil valioso para sí mismo, pero también válido para quienes vienen detrás de él, los jóvenes destinatarios de su conversación, sus sobrinos. El valor que concede a esta posibilidad para su vida se expresa en el disfraz que elige del viejo baúl forrado de terciopelo azul de su abuela: la camisa de templario (Jiménez Loza- 
no, 2013: 159). Esta elección volverá a plantearse al final de su vida, cuando tenga que elegir la mortaja de entre las vestiduras asociadas a las diferentes cruzadas que ha vivido: miliciano, médico, alférez provisional, franciscano (como Cervantes). Finalmente, se inclina por el hábito que los reúne todos: «-Pero acordaos, antes que de otra cosa cualquiera, de los Cruzados y sobre todo de la cruz roja del Temple, que hay que llevar siempre, vivo o muerto» (Jiménez Lozano, 2013: 98).

La estima por este ideal es tal, que los amores de Lodares y Lisa María de las Nieves se describen como un vuelo imaginario del cruzado y su amada por el cielo de Oleza. También se manifiesta en las representaciones teatrales en las que participa Lodares («hacía el papel de un caballero que era tan valiente como Tristán y renunciaba a sus derechos de primogenitura para irse a las cruzadas», Jiménez Lozano, 2013: 160), y que simbolizan el ideal que se persigue «siendo ya mayorcito y estando en el último curso de bachillerato» (Jiménez Lozano, 2013: 160).

Pedro Manuel Martín Lodares vive en el tiempo de las Cruzadas mientras es joven. Confiesa a sus hermanas que le pasa exactamente igual que a la princesa Bibiesco, que lloraba por la pérdida de Constantinopla porque le parecía que había sido la víspera «y todavía no se había repuesto» (2013: 142); Lodares llora por la desaparición del mundo donde habitaron los cruzados. Los viajes y desplazamientos imaginarios que permiten la literatura y la historia están también marcados por la cruz roja. Una cruz en el tren que une los lugares familiares (Madrigal de las Altas Torres, Encinasola de los Comendadores) con Constantinopla y Alejandría, dibujando así nuevos mapas: «y ver luego, al bajar del tren, la maravillosa rueda roja de la locomotora, como la Cruz de un Templario» (2013: 133).

Esa inmediatez de las Cruzadas es posible gracias a los relatos vivos de sus aventuras, desventuras y atrocidades en el Colegio Francés de Oleza, donde la revisión de los exilios de los caballeros no está idealizada, sino presentada en sus contradicciones: «Cruzadas y Cruzadas dieron santos y asesinos, violadores, ladrones y anacoretas o místicos» (2013: 170). A pesar de estas contradicciones, Lodares considera que su grandeza estaba en que en aquel tiempo cabía esperar lo imposible: «porque aquellos siglos eran siglos verdaderos y se podía vivir en ellos, y esperar los imposibles y, al fin, éstos llegaban» (2013: 171).

Toda la trayectoria de Lodares, su existencia concreta en el siglo XX, está vivida en relación con las Cruzadas, y lo que resulta de esta comparación es un juicio durísimo sobre el momento de estas nuevas «cruzadas» que le ha tocado vivir, las de la Guerra Civil española desde los dos bandos. Lleva consigo el sabor amargo de su terrible verdad: «que las calaveras huecas, atadas a una soga, y repiqueteando sobre los cantos rodados de una calle empedrada, eran la única verdad de este mundo, que tío Pedro había visto, y luego tocado en la Cruzada» (2013: 172). Siente en sus huesos, y en este sentido se actualiza el título, lo que debieron de sentir a su regreso los Cruzados: 
nuestro tío Pedro era como un Cruzado antiguo, de los que cuando volvían ya no era su tiempo, y a lo mejor su mujer se había vuelto a casar, y sus hijos se habían repartido ya sus bienes, creyéndole muerto; y todo le era extraño, no tenía con quién hablar ni de qué hablar, y hasta tenía que inventarse un pasado, y no decir nunca lo que había sido de verdad, porque entonces le reconocían y comenzarían a odiarle. Así que lo que quería era morirse, y por eso a lo mejor tenía tanta prisa tío Pedro en contarnos, a nosotros, las fábulas de la Cruzada (2013: 165).

Lodares se siente extraño: «y te apedrean los chicos en la calle y se ríe todo el mundo, pero enseguida te das cuenta de que es porque eres y vas vestido de otros siglos muy antiguos» (2013: 165). En este proceso de viaje desde el pasado al presente y al revés, se entiende el origen del juicio crítico de Lodares sobre sus «cruzadas», que han perdido el sentido de las antiguas y se lo pregunta: «¿Se oye acaso ahora el Ángelus de la mañana, del mediodía y del atardecer, que nos recordaba que el mundo y nosotros íbamos a algún sitio, y podíamos pisar fuerte en el camino?» (2013: 11). Lodares lleva con él el peso de la sangre y el mal de la historia y se lo cuenta a los chicos: no ha podido consolar al Ángel de la Historia que lloraba por un mundo roto por su eje y les augura algo mejor que lo que él ha visto: «Tampoco habéis visto lo enrojecida de sangre que está esa esfera en algunas partes. Ni Dios quiera que la veáis nunca, y no podáis ver partido el eje del mundo, ni al Ángel desconsolado» (2013: 11).

La posibilidad que se abre cara al futuro es la de ser un «cruzado verdadero» en el presente y esto significa rechazar y limpiarse de «los pensamientos y deseos de odio o de desprecio. El país entero, como él mismo, había sido adoctrinado en éstos, y por eso, pese a todo y después de todo, algo de baba espesa y sucia siempre quedaba en el alma de los españoles» (2013: 148).

\section{ORIGINALIDAD DE RETORNO DE UN CRUZADO}

La originalidad de la novela descansa en la centralidad del personaje y en su cualidad de contador, que permite ligar los hipotextos y las historias. El narrador no lo es en sentido pleno, según escribía Benjamin (1973: 301-305), si no ha tenido una experiencia de las cosas, de la historia, contrastada con una sabiduría que viene de otras experiencias memorables ${ }^{19}$. La configuración de Lodares como personaje se sustenta en el conjunto de «pensares y sentires» de los que habla su creador, se perfila a partir de lo que cuenta de sí y de los términos de comparación y complicidad que busca el narrador para

\footnotetext{
${ }^{19}$ Para los estudios sobre la concepción de la memoria en la obra de Jiménez Lozano hay estudios muy importantes de Reyes Mate (1994), William Sherzer (2003), Francisco Javier Higuero (1990, 1993, 1994 y 2013), Santiago Moreno (2010). Para el tema particular de la relación con los postulados de Benjamin, véanse los de Ana Calvo Revilla (2011 y 2013).
} 
componer su riqueza, y se completa con los secretos que sobre él se revelan en un coloquio familiar.

La originalidad de la novela radica en el personaje. Se confirma su centralidad en los niveles sintáctico, como unidad de sentido, y pragmático. La importancia de esta categoría es rotunda en el texto desde el título que lo anuncia, pasando por la presentación de su actividad de contador de historias que hacen de él quién es, tanto como por el encaje de las intertextualidades que nutren la figura de Lodares, o por aquellos elementos pragmáticos que hemos visto al presentar su génesis.

El personaje, unidad sintáctica y de sentido de la novela (Bobes, 1993), se configura en una naturaleza dual: Lodares es narrador, su historia se conoce a través de la acción que le caracteriza, es decir, el contar. Dándose a través de las palabras, se relaciona con sus sobrinos. Por ello, el ser de Lodares se refleja en su sobrino, con quien comparte la tarea de contar. Así el contador de historias (Lodares) y el narrador de lo que ha escuchado (sobrino) se unen en una estructura narrativa que se reparte en los dos polos de la narración. El eje en el que descansa la originalidad de la novela es el personaje como contador de historias, los polos son tío-sobrino. Los dos polos narrativos se unen en lo que cuentan: las historias del tío Pedro.

Lodares, como contador, quiere dejar en herencia a sus sobrinos el juicio sobre el sentido y los sinsentidos de la historia; por otro lado, el narrador y sobrino de Lodares es interlocutor de las historias contadas y narrador que testimonia lo contado. En torno a este eje de la novela, la relación entre protagonista y narrador (tío-sobrino) se agrupa el resto de las categorías (espacios, otros personajes, tiempo, ordenación de las historias en el discurso, intertextos, etc.). La función que cumple en el coloquio permite acceder a la originalidad de la novela y a su significado.

Lodares se presenta como víctima de la historia que ha tenido que padecer. Se sabe por su sobrino que «llegó a casa roto y como en desespero» (2013: $154)$, que está muy enfermo $(2013: 13,165)$, que le queda poca vida — «pronto no le volveríamos a ver» (2013: 12)_ , y que ya no tiene deseos de vivir: «Es que ya no es mi tiempo y a veces quiero irme» (2013: 13). Se cuenta que está «herrando el caballo» para ir a la siguiente Cruzada, la última (2013: 26) y que hay días que «no podía o no quería levantarse de la cama» (2013: 74). Se dice que su retorno es como el de un mendigo que vuelve sin bolsa (2013: 48), que ha recibido «muchas saetas y tiros de espingarda en todas partes, y éstas eran las reliquias de la guerra que, luego, le habían acarreado la enfermedad que tenía» (2013: 164), y que llega «con ese secular cansancio, pegado a su cuerpo y a su alma» (2013: 74). Está aquejado «de una melancolía y tristura muy profundas y se juntaban con sus males para acabar con su cuerpo». Las hermanas saben que «la salud de su hermano no daba para mucho tiempo» (2013: 79). Pese a que todos intentan que se cure de «sus heridas y esquinazos con el mundo, que eran tantos» (2013: 74), se sabe que se está muriendo 
(2013: 79). Aun así, en la versión definitiva de la novela, Lodares no muere, sino que el lector lo despide dormido, aunque entreviendo su partida definitiva, o mejor, su llegada al destino de su última Cruzada. En este punto, señala inquisitivo el narrador: «¿Y adónde pensaría tío Pedro que había llegado?» (2013: 173).

Lodares retorna a casa y, en rebelión con la historia que tantas víctimas se ha cobrado, transmite a sus sobrinos sus heridas y duelos. Su peripecia se hermana con la de las víctimas de la historia, con los que han pasado inadvertidos entre sus grandes masacres, o han sido considerados nada por los poderosos. Con este propósito se presentan diversas figuras a las que Lodares da prioridad en su relato: el tonto del pueblo, salvado de dos fusilamientos, uno de cada bando, porque dice verdades (2013: 39); el inocente ruso que se resiste a morir porque antes tiene que volver a su isba y despedirse de un icono que le había regalado su madre «de Cristo que dormía con un solo ojo y podía cuidarle a él en el ataúd hasta que despertase» (2013: 46); el payaso que dice verdades entre risas «con un traje rojo, amarillo y verde» (2013: 68); el Ángel de la Historia que llora «desconsolado» (2013: 12); el obispo leproso que se compadece de los niños que «morían de hambre, y ni siquiera podía oírlos llorar porque los llantos de un corderillo casi muerto no tienen fuerza para llegar a parte alguna» (2013: 119); los esclavos que eran vendidos como carne durante las cruzadas (2013: 100); las criaturas de todo tiempo tratadas como «reses humanas» (2013: 100); o los niños discapacitados sometidos a burlas: «e hicieron mofa de unos niños tullidos, o muy delgaditos y con la cabeza muy grande, que algunas veces sacaban unas monjas de paseo, e iban al campo para que Dios los bendijese allí y los limpiase de la risa y de la compasión científica de las gentes que estaban sanas y con el pestorejo gordo» (2013: 123).

Con el fondo de esta galería de personajes, se entiende mejor el destino que persigue Lodares en todas las cruzadas, las forzosas y las imaginadas. Se trata de rescatar la cruz de las entrañas de la tierra, pues es la única que recoge a todas las víctimas de la historia. Así, cuando los sobrinos le preguntan por la siguiente cruzada, responde: «Pero vosotros preparaos, por si acaso, con vigilias y velas encendidas hasta que luzca luego la estrella matutina, el lucero del alba, la señal de la partida. Y os pongáis en marcha» (2013: 102). También les dice que todo lo que él ha contado es para que hagan cuentas con los personajes y las historias de los personajes que él ha traído al hilo de la narración: «Vosotros veréis luego cómo acomodáis, allí y sobre todo dentro de vosotros mismos, a toda la gente de la que os he hablado, y que ya estáis obligados a acoger» (75). Y añade: «y ¡ojalá — decía- que esas gentes de las que nos hablaba no se nos murieran con el frío de ahora mismo y sus desprecios! Y ojalá no las matéis vosotros, sin quererlo, por no andar, delante de ellos, con el alma de puntillas!» (2013: 75). Este consejo de andar con extraordinario cuidado para no dañar a ninguna de las criaturas humildes que han 
pasado por los márgenes de los relatos es preocupación y rasgo de la manera de escribir del escritor abulense. Así lo ha señalado Francisco Javier Higuero: «En la obra narrativa del escritor aquí estudiado, el otro aparece bajo la forma textual de personajes insertos en el ámbito existencial de la intrahistoria, los cuales se caracterizan por rasgos claramente definidos como indigentes. Es tal condición de seres humillados y ofendidos la que hace que estos personajes puedan ser denominados anamnéticos» (1994: 64)

El coloquio sería imposible sin los sobrinos, esenciales en la narración una vez que el narrador decide hacerlos testigos de sus historias y depositarios de sus experiencias. En el relato del sobrino se recoge la herencia del tío que, lógicamente, se divide en las huellas del mundo ensangrentado y la belleza pisoteada, por un lado, y por otro, en los despuntes de esperanza y de hermosura irreductibles. Se abre así espacio a la polisemia del término «mundo» que el mismo escritor reconocía: «La polisemia de esta palabra "mundo" está por lo demás en la base de las aparentes contradicciones. Mundo es la maravilla del ser y del vivir, y también es la trama de iniquidad o sacrificio de víctimas para que todo siga igual» (correo del 14 de marzo de 2012).

Sería muy largo el análisis de los dos polos recogidos por el narrador. El mundo ensangrentado es el de la guerra y la muerte (2013: 48), el llanto y el desconsuelo (2013: 12), la destrucción de la belleza (2013: 23), la irracionalidad (2013: 25), la podredumbre (2013: 29), los lazaretos y la enfermedad (2013: 99), etc. El mundo del ser y del vivir es el del amor verdadero (2013: 50), el de las tertulias y el saber (2013: 55), el de los correos y las estaciones que comunican noticias y amores (2013: 82), el de las clases y la transmisión de los saberes (2013: 88-90), el de las tertulias familiares en torno a una mesa camilla (2013: 93), el de los balnearios (2013: 119 y ss.), etc.

Para entender la originalidad de la obra es fundamental también identificar esas historias del tío Pedro que se modifican al llegar a sus interlocutores. La presencia de oyentes, atentos a los relatos, no es aleatoria en la narración; antes bien, la intención del contador de que su experiencia y su juicio crítico permanezcan en el alma de los jóvenes le obliga a descender hasta las profundidades de sus historias y, por tanto, a no contentarse con el peso del mal. Este peso domina el ánimo del cansado y herido Lodares que, sin embargo, no puede dejar de contestar a la pregunta de Lisa: « $i$ Y no nos gustan a nosotros, los de nuestra familia, las cosas tan bonitas que hay en el mundo?» (2013: 52), pregunta que se abre hacia una atención y consideración de los otros secretos del mundo que no devora la iniquidad. Basten algunos ejemplos de cómo se produce este paso de la visión del mundo rojo y macabro a su otra dimensión de mundo vivible. En las primeras páginas de la novela se describe la esfera del mundo: «...lo enrojecida de sangre que está esta esfera en algunas partes [y] partido el eje del mundo» (2013: 12). Esta imagen del mundo ensangrentado y partido por su eje vuelve a aparecer al final del capítulo III, pero inserto en una dinámica distinta. Ya se ha desarrollado parte del coloquio entre 
los chicos y el tío, y ellos se atreven a preguntar, forzando a Lodares a señalar otra posibilidad extrahistórica (Dios) que pueda ser histórica (sostén del mundo):

$-¿$ Y qué vamos a esperar de una rueda que se ha salido del eje, o éste se ha roto? Pues que dé vueltas a lo tonto y a lo loco ¿no? Lo lógico.

Aunque luego, a lo mejor, después de un rato pequeño, si veía que nos dejaba a todos tristes o como no entendiendo del todo lo que había dicho [...] añadía:

-A menos que Dios nos oiga y ponga su mano encima, o sostenga la bola del mundo donde estamos» (2013: 78).

La descripción de las calaveradas y de los infiernos de risas sarcásticas de demonios hambrientos de sangre son, como se ha visto, un motivo presente a lo largo de la novela. Y se repite hasta el punto de que Lodares parece no creer que la esperanza sea posible; ni quiere oír hablar de ella: «¿No sabéis que los griegos decían que se le escapó a Pandora de una caja y era como una sierpe que extendía con su veneno las desgracias» (2013: 77). Pero matiza cuando la describe encarnándola en una niña frágil ${ }^{20}$ y pide a sus sobrinos que se la lleven: «Traedla vosotros, y sentadla aquí a mi cabecera en la silla de paja pequeñita. Es más joven que Lisa y más delgaducha que ella ¿qué os creíais? Abulta lo que una alondra, pero es el poder de Dios, y es muy hermosa (2013: 77). Esta petición obliga a Lodares a dar cuenta de su experiencia de manera más completa, es decir, le devuelve a la memoria otro episodio de su historia: la cárcel que padece tras la contienda civil y cómo desde la ventana de la prisión ve a una niña: «él la había puesto el nombre de Esperanza y [...] ella sí sabía que él era un preso y no podía salir de allí sino cuando los que mandaban quisieran, pero le invitaba a jugar con ella riéndose» (2013: 77).

La descripción de los leprosos es también objeto de transformación a través del relato y de esta relación beneficiosa entre el tío y los sobrinos. Lodares cuenta que el mayor dolor de los enfermos no era vivir apartados de la gente, sino separados en las mismas iglesias: «y, como ya muchos no tenían ni labios para rezar clamando al cielo, sólo se oía un rumor de moscarrones o ayes y también los ruidos de las carcajadas y los ascos, si alguien los veía» (2013: 99). Se describe a continuación su carne blanca y reluciente — «como los mosaicos mismos de la iglesia y como se decía que la tendrían transfigurada los resucitados de las sepulturas del Día del Juicio» (2013: 99)—, en términos similares a los de la piel transparente del obispo que lleva en su cuerpo el dolor de los pobres.

La educación también se manifiesta de diversas formas en el relato. Se contrasta la descripción terrible de las pretensiones antieducativas durante la Guerra Civil, cuando los barberos se convertían en maestros porque con na-

\footnotetext{
${ }^{20}$ Como una niña pequeña definía Charles Péguy la esperanza, que iba de la mano de sus dos hermanas fuertes: la fe y la caridad (1993).
} 
vaja en mano tenían la última razón (2013: 24-25) con el Colegio Francés de Oleza, caracterizado por los buenos maestros y el gusto por la unidad del saber. De este modo, la expresión más alta de la educación es la conversación en torno a una mesa camilla en la que Pedro y sus sobrinos aprenden el sentido del vivir: «nos sentábamos allí a una mesa camilla de nogal, como para la eternidad entera según decía mamá, en la que estaríamos en el cielo en torno a otra mesa indeciblemente enorme, pero muy casera» (2013: 93).

Las enseñanzas de Pedro Lodares nacen de la experiencia probada en carne propia y aprendida por la historia; comparadas con otras narraciones, se transmiten a sus sobrinos a través de la conversación. Porque, como ha dicho muchas veces Jiménez Lozano, el final de la Historia será memoria passionis o reunión de todas las historias. Para eso se necesitan, narradores que acopien esas historias verdaderas. Entre tanto, Jiménez Lozano, cede la palabra a Lodares y éste, a su vez, a su sobrino.

\section{CONCLUSIONES}

Tras el estudio de la novela Retorno de un cruzado, se puede concluir, en primer lugar, que los comentarios autoriales sobre la escritura de la obra ilustran la factura de un texto de compleja génesis. De las seis variantes de la obra, es destacable la segunda versión que añade un nuevo capítulo, el IX, que en la definitiva se suprime por razones de tono y coherencia literarios.

En segundo lugar, Retorno de un cruzado presenta una rica combinación y recreación de textos literarios anteriores enraizados en la estructura misma de la novela. La vida de Lodares se entrelaza con los conflictos entorno a la Guerra Civil española de 1936, y se establece en intertextualidad literaria con obras anteriores: una situada en el frente muerto de Aragón, por lo que hay complicidad con Incierta gloria (2012), de Joan Sales; otra con la situación de Madrid en el periodo prebélico, para este segundo episodio se establece una complicidad con Miserias de la guerra, de Pío Baroja (2006). Además la infancia y educación del protagonista se nutre del ambiente de Oleza, ciudad pintada por Miró en sus novelas de Orihuela: Nuestro Padre San Daniel: novela de capellanes y devotos (1921) y El obispo leproso (1926). Otro referente literario que sirve en la construcción de la novela es el del Quijote, ahora si el cervantino vivía gracias a la ilusión de ser caballero andante, el personaje jimenezlozaniano vive dolorido por las cruzadas que ha visto y protagonizado.

Por último, se ha visto que la presencia de esta serie de textos e hipotextos se articulan a través del personaje protagonista que los actualiza, asume, recrea o revive en su experiencia particular. Lodares vive gracias a las historias que le preceden. A su vez el tejido entre las partes se cose a través de un segundo modo de concitar la unidad: el interlocutor y narrador fingido, uno de los sobrinos del protagonista, que recoge los recuerdos de las historias es- 
cuchadas en charla con su tío. La conversación es el medio para llegar a descubrir el quid de la cuestión, es decir, el significado, en cuanto permite la reunión y sentido de las partes. Es la cruz lo que está en la base de las diferentes cruzadas del protagonista, es la cruz lo que se oculta en medio de las historias sangrientas de los hombres y es su búsqueda lo que se propone como hipótesis de significado a los interlocutores de los relatos de Lodares.

\section{BIBLIOGRAFÍA CITADA}

Anthropos (Número monográfico sobre José Jiménez Lozano) (1983). 25.

Anthropos (Número monográfico sobre José Jiménez Lozano) (2003). 200.

Arbona Abascal, Guadalupe (2008). El acontecimiento como categoría del cuento contemporáneo. Las historias de José Jiménez Lozano. Madrid: Arco Libros.

Arbona Abascal, Guadalupe (2013). «Posfacio», en José Jiménez Lozano, Retorno de un cruzado. Madrid: Ediciones Encuentro.

Azorín (2006). «La fragancia del vaso», en Castilla. Madrid: Edaf, pp. 95-100.

Baroja, Pío (2006). Miserias de la guerra. Las Saturnales. Miguel Sánchez Ostiz (ed.). Madrid: Caro Raggio.

Benjamin, Walter (1973). «El narrador», Revista de Occidente. 129, pp. 301-333.

Bobes Naves, María del Carmen (1993). «El personaje novelesco: cómo es, cómo se construye», en Marina Mayoral (coord.), El personaje novelesco. Madrid: Cátedra.

Calvo Revilla, Ana (2005). «La apuesta ética y estética de la obra literaria en José Jiménez Lozano», en Ana Calvo (ed.), Cultura y Sociedad. Madrid: Instituto de Humanidades Ángel Ayala, pp. 61-90.

Calvo Revilla, Ana (2006a). «José Jiménez Lozano: pensamiento crítico y escritura en el oficio de escribir y narrar», en Actas del VII Congreso Congreso Católicos y Vida pública: «Llamados a la libertad» I. Madrid: CEU Ediciones, pp. 1035-1048.

Calvo Revilla, Ana (2006b). «Rasgos lingüísticos que configuran el discurso literario en Los grandes relatos de José Jiménez Lozano», en Victoria Romero Gualda, Manuel Casado Velarde y Ramón González Ruiz (ed.), Análisis del discurso: lengua, cultura, valores I. Madrid: Arco Libros, pp. 263-276.

Calvo Revilla, A. (2011): «José Jiménez Lozano y Walter Benjamín: historia, memoria y narración», en Ignacio Blanco Alfonso y Pilar Fernández Martínez (coord.), Entre la ficción y la realidad. Perspectivas sobre periodismo y literatura. Madrid: Fragua, pp. 112-128.

Calvo Revilla, A. (2013). «Las perplejidades de la posmodernidad en el pensamiento de José Jiménez Lozano», Rilce. 29.1, pp. 5-24.

Conte, Rafael (1994). «El narrador y su mundo. Una literatura de salvación», en José Jiménez Lozano, Premio Nacional de las Letras Españolas 1992. Madrid: Ministerio de Cultura, pp. 111-114.

Domingo, Teresa (2002). «Talante y escritura: Maestro Huidobro, de José Jiménez Lozano», Espéculo. Revista de estudios literarios [en línea]. 20, s. p., disponible en $<$ https:// pendientedemigracion.ucm.es/info/especulo/numero20/huidobro.html> [ref. de 11/7/16].

Fernández Urtasun, Rosa (2006). «Algunas reflexiones sobre la poética de José Jiménez Lozano. Un estudio de El narrador y sus historias», en Álvaro de la Rica (ed.): Homenaje a José Jiménez Lozano. Actas del II Congreso Internacional de la Cátedra Félix Huarte. Pamplona: Eunsa, pp. 63-78.

Forbelsky, J. (2006). «José Jiménez Lozano, escritor fuera y dentro de su tiempo», en Álvaro de la Rica (ed.): Homenaje a José Jiménez Lozano. Actas del II Congreso Internacional de la Cátedra Félix Huarte. Pamplona: Eunsa Ediciones Universidad de Navarra, pp. 19-28. 
Genette, Gérard (1989). Palimpsestos. La literatura en segundo grado. Celia Fernández Prieto (trad.). Madrid: Taurus.

González, José Ramón (ed.) (2003). José Jiménez Lozano, Nuestros Premios Cervantes. Valladolid: Universidad de Valladolid-Junta de Castilla y León.

González Sainz, José Ángel (2003). «Escribir como si se pusiera una vela (La índole de la belleza)», en José Ramón González (ed.), José Jiménez Lozano, Nuestros Premios Cervantes. Valladolid: Universidad de Valladolid-Junta de Castilla y León, pp. 131-144.

Gracia, Jordi y Domingo Ródenas (coord.) (2011). «Derrota y restitución de la modernidad 1939-2010», en José-Carlos Mainer (dir.), Historia de la literatura española, vol. 7. Madrid: Editorial Crítica.

Guillén, Claudio (1985). Entre lo uno y lo diverso. Introducción a la literatura comparada. Barcelona: Crítica.

Gullón, Ricardo (dir.) (1993). Diccionario de la Literatura Española e Hispanoamericana. Madrid: Alianza Editorial.

Galparsoro, Gurutze y José Jiménez Lozano (1998). Una estancia holandesa. Barcelona: Anthropos.

Higuero, Francisco Javier (1990). «Multiplicidad funcional de la memoria en cuatro cuentos de José Jiménez Lozano», Lucanor. 5, pp. 39-57.

Higuero, Francisco Javier (1991). La imaginación agónica de Jiménez Lozano. Barcelona: Anthropos.

Higuero, Francisco Javier (1993). La memoria del narrador. Intertextualidad anamnética en los relatos breves de Jiménez Lozano. Valladolid: Ámbito.

Higuero, Francisco Javier (1994): «El fondo intrahistórico de la narrativa de Jiménez Lozano», en José Jiménez Lozano, Premio Nacional de las Letras Españolas 1992. Madrid: Ministerio de Cultura, pp. 61-79.

Higuero, Francisco Javier (1995). «Metanarración oral en Los grandes relatos, de Jiménez Lozano», en Gregorio C. Martín (ed.), Selected Proceedings of the Pennsylvania Foreign Language Conference (1991-1992). Pittsburg: Duquesne University, pp. 143-151.

Higuero, Francisco Javier (1999): «Los tres niveles intradiegéticos del recuerdo en Los compañeros, de Jiménez Lozano», Versants. Revue Suisse des Littératures Romanes. 35, pp. $25-45$.

Higuero, Francisco Javier (2013). Recordación intrahistórica en la narrativa de Jiménez Lozano. Madrid: Ediciones del Orto.

Jiménez Lozano, José (1973). La salamandra. Barcelona: Destino.

Jiménez Lozano, José (1982). Duelo en la casa grande. Barcelona: Anthropos.

Jiménez Lozano, José (1987). «E la Guerra Civile divenne una Crociata», Storia-Dossier. Ottobre, pp. 19-22.

Jiménez Lozano, José (2000a). Un hombre en la raya. Barcelona: Seix Barral.

Jiménez Lozano, José (2000b). Retratos y naturalezas muertas. Madrid: Trotta.

Jiménez Lozano, José (2003). El narrador y sus historias. Madrid: Publicaciones de la Residencia de Estudiantes.

Jiménez Lozano, José (2008). Los cementerios civiles y la heterodoxia española. Barcelona: Seix Barral. Primera edición de Madrid: Taurus, 1978.

Jiménez Lozano, José (2010). Un pintor de Alejandría. Madrid: Ediciones Encuentro.

Jiménez Lozano, José (2013). Retorno de un cruzado. Madrid: Ediciones Encuentro.

Jiménez Lozano, José y Guadalupe Arbona Abascal (2010). «El aroma del vaso», en Javier Prades y Eduardo Toraño (ed.), La razón de la esperanza. Madrid: Publicaciones de la Facultad de Teología San Dámaso, pp. 161-193.

José Jiménez Lozano: Premio Nacional de las Letras Españolas 1992 (1994). Madrid: Ministerio de Cultura.

Kristeva, Julia (1978). Semiótica. Madrid: Fundamentos. 
Martínez Díaz, Alicia Nila (2011). Los personajes femeninos en la novela de José Jiménez Lozano (Tesis doctoral en línea). Madrid: Universidad Complutense, en <http://eprints.sim. ucm.es/14436/1/T33404.pdf> [ref. de 11/7/16].

Martínez Fernández, José Enrique (2001). La intertextualidad literaria. Madrid: Cátedra.

Mate, Reyes. (1994). «Narración y memoria. Reflexiones filosóficas sobre la obra de Jiménez Lozano», en José Jiménez Lozano, Premio Nacional de las Letras Españolas 1992. Madrid: Ministerio de Cultura, pp. 47-60.

Medina-Bocos, Amparo (2005). «Introducción», en José Jiménez Lozano, Antología de cuentos. Madrid: Cátedra, pp. 13-26.

Miró, Gabriel (1943). Obras Completas. Madrid: Biblioteca Nueva.

Morelli, Giovanni y Danillo Manera (2007). «Narrativa spagnola contemporanea», en Letteratura spagnola del Novecento. Dal modernismo al postmodern. Milán: Bruno Mondadori.

Moreno González, Santiago (2008). El exilio interior de José Jiménez Lozano. Estudio de una propuesta narrativa singular (Tesis doctoral en línea). Murcia: Universidad, en $<\mathrm{http}$ :/ /hdl.handle.net/10803/10959>.

Moreno González, Santiago (2010). «Libertad e inconformismo: sobre la concepción del relato de José Jiménez Lozano», Revista de Literatura. 144, pp. 455-478.

Orr, Mary (2003). Intertextuality. Debates and Contexts. Cambridge: Polity Press.

Péguy, Charles (1993). El Misterio de los Santos Inocentes. Madrid: Ediciones Encuentro.

Piedra, Antonio (1989). «Introducción», en José Jiménez Lozano, Sara de Ur. Madrid: Espasa Calpe, pp. 9-59.

Piedra, Antonio (ed.) (2005). José Jiménez Lozano: Premio Provincia de Valladolid 1996 a la Trayectoria Literaria. Valladolid: Editora Provincial.

Pozuelo Yvancos, José María (2003). «José Jiménez Lozano: fábulas pequeñas de historias memorables», en José Ramón González (ed.), José Jiménez Lozano, Nuestros Premios Cervantes. Valladolid: Universidad de Valladolid-Junta de Castilla y León, pp. 47-80.

Rica, Álvaro de la (ed.) (2006). Homenaje a José Jiménez Lozano. Actas del II Congreso Internacional de la Cátedra Félix Huarte. Pamplona: Eunsa.

Rico, Francisco (dir.) (2000). Historia y crítica de la literatura española, vol. 9. Los últimos nombres: 1975-1990. Barcelona: Crítica.

Sales, Joan (2012). Incierta gloria. Barcelona: Destino.

Sanz Villanueva, Santos (1984). Historia de la literatura española 6/2. El Siglo XX: literatura actual. Barcelona: Ariel.

Sanz Villanueva, Santos (2010). La novela española durante el franquismo. Itinerarios de la anormalidad. Madrid: Gredos.

Sherzer, W. M. (1994): «El yo errante de José Jiménez Lozano José Jiménez Lozano», Premio Nacional de las Letras Españolas 1992. Madrid: Ministerio de Cultura, pp. 119-124. Impreso.

Sherzer, W. M. (2003): «José Jiménez Lozano: la conciencia dentro de la novelística», Siglo XXI. Revista de la Cátedra Miguel Delibes. 1, pp. 215-219.

Steiner, George (2007). Presencias reales. Juan Gabriel López-Guix (trad.). Barcelona: Destino.

Fecha de recepción: 8 de abril de 2014 .

Fecha de aceptación: 29 de octubre de 2014. 